\title{
Nhanderekô Eg Kanhró: o audiovisual fortalecendo a escola indígena
}

\author{
Nhanderekô Eg Kanhró: audiovisual strengthening the indigenous school
}

\author{
Monica Panis Kaseker* \\ Lucas Fernando Ribeiro** \\ Yago Junio Queiroz***
}

\begin{abstract}
Resumo
O artigo apresenta a experiência desenvolvida no projeto Entre os saberes da escola indígena e da universidade: a comunicação audiovisual como elemento de expressão, articulação e fortalecimento da organização dos professores indígenas. Com o nome indígena Nhanderekô Eg Kanhró, em Guarani e Kaingang, o projeto discute o que seria o "nosso jeito" de educar nas escolas indígenas. A produção audiovisual foi utilizada como estratégia de expressão, articulação e fortalecimento das especificidades da Escola Indígena. Foram desenvolvidas oficinas colaborativas de produção audiovisual e rodas de conversa inspiradas no pensamento de Paulo Freire (1985) e no projeto Vídeo nas Aldeias (ARAÚJO, 2015; PINHANTA, 2004). Para a produção científica, nos baseamos na noção de participação observante de Wacquant (2002).
\end{abstract}

Palavras-chave: Comunicação audiovisual. Educação indígena. Identidade. Interculturalidade.

\begin{abstract}
This article is an experience report on the project Between the knowledge of the indigenous school and the university: audiovisual communication as an element of expression, articulation and empowerment of indigenous teachers. Nicknamed Nhanderekô Eg Kanhró, in the Guarani and Kaingang languages, the project reflects on the "our way" of teaching in indigenous schools. It was proposed the audiovisual production use as a strategy for expression, articulation and empowerment about specificities of Indigenous School. The methodology includes collaborative workshops of audiovisual production and chats, inspired by the ideas of Paulo Freire (1985) and the experience of the Video nas Aldeias (ARAÚJO, 2015; PINHANTA, 2004). We are based on the notion of observing participation of Wacquant (2002).
\end{abstract}

Keywords: Audiovisual communication. Indigenous education. Identity. Interculturality.

\footnotetext{
* Doutora em Sociologia pela UFPR, com período sanduíche na UAM-X DF/México. Jornalista e professora do Programa de Pós-Graduação em Comunicação e da Graduação em Jornalismo da UEL.

** Jornalista. Mestrando em Comunicação na Universidade Estadual de Londrina (UEL).

*** Graduado em Jornalismo pela Universidade Estadual de Londrina. Bolsista Kaingang Fulniô do Projeto Nhanderekô Eg Kanhró.
} 


\section{Introdução}

Nos últimos quatro anos, ao longo de ações extensionistas desenvolvidas por equipes da Universidade Estadual de Londrina (UEL), foram levantadas algumas necessidades socioeducativas junto aos professores indígenas, gestores das escolas estaduais indígenas e caciques das terras indígenas da região norte do Paraná. Diante dessas demandas, foi proposto o projeto Entre os saberes da escola indígena e da universidade: a comunicação audiovisual como elemento de expressão, articulação e fortalecimento da organização dos professores indígenas, que ganhou o apelido Nhanderekô Eg Kanhró, em Guarani e Kaingang respectivamente, que pode ser traduzido como "nosso jeito" de educar.

No Paraná, o processo de estadualização das escolas indígenas começou em $2007^{1}$, com o reconhecimento da contratação e atuação de professores indígenas bilíngues nas escolas indígenas. No entanto, a Rede Estadual de Educação do Paraná ainda requer acompanhamento permanente e de formação continuada dos professores indígenas, o que não é atendido pelo Estado, para qualificar a escolarização das crianças e jovens Kaingang, Guarani e Xetá.

Somente a partir da Lei de Diretrizes e Bases da Educação Nacional (LDBEN) de 1996 e das Diretrizes Curriculares Nacionais da Educação Escolar Indígena (Parecer CNE/CEB no. 14/1999, posteriormente atualizado pelo Parecer no. 13/2012) é que houve o reconhecimento dos professores indígenas bilíngues no Brasil.

Os processos progressivos de desvalorização das línguas indígenas, assim como a organização escolar e curricular, têm enfraquecido o uso cotidiano das línguas Kaingang e Guarani. Mesmo com dificuldades na reorganização da gestão, na proposta curricular e tendo ainda participação minoritária dos professores indígenas em suas equipes, essas escolas vêm ampliando sua oferta de ensino fundamental e de ensino médio. Observa-se, ainda, fragilidades na relação entre as equipes das escolas estaduais indígenas com os caciques e lideranças indígenas, inviabilizando a avaliação e elaboração de propostas curriculares na perspectiva de se fortalecer as políticas linguísticas em cada comunidade. Uma das questões diagnosticadas em ações extensionistas realizadas anteriormente foi sobre a presença de acadêmicos indígenas dessas comunidades vinculados à cursos de licenciatura na Universidade Estadual de Londrina (UEL), na Universidade Estadual de Maringá (UEM) e na Universidade Estadual do Norte do Paraná (UENP), e que demandariam

\footnotetext{
${ }^{1}$ Parecer CEB/CEE no. 423/2007.
} 
fortalecer sua presença e atuação nas escolas de suas aldeias. Constatou-se que havia a necessidade de articulação dos acadêmicos indígenas com as equipes pedagógicas das escolas indígenas e com as lideranças de suas comunidades, contribuindo na integração da educação superior com a educação básica, por meio do diálogo possível entre os conhecimentos acadêmicos, os conhecimentos escolares e os conhecimentos tradicionais indígenas (AMARAL, 2016).

Nesse sentido, o projeto Nhanderekô Eg Kanhró desenvolveu ações de sistematização e produção de material de apoio pedagógico com os professores e gestores indígenas numa perspectiva crítica, bilingue e intercultural, bem como para o fortalecimento de uma rede permanente das escolas indígenas dessa região. Entre essas ações, foram incluídas práticas comunicativas para ajudar na articulação e integração cultural entre os saberes da escola indígena e da universidade, como o uso do audiovisual.

A comunicação audiovisual consiste numa forma eficaz diante da forte vocação oral dos povos indígenas, especialmente porque a capacidade expressiva das imagens engloba aspectos fundamentais da comunicação indígena: a oralidade e a corporalidade. A metodologia das oficinas buscou a utilização da comunicação audiovisual para dar visibilidade às expectativas, intenções e desejos da comunidade escolar indígena acerca da escola que querem construir e da universidade que desejam acessar.

Neste artigo, a proposta é refletir sobre este processo de produção, no qual a comunicação audiovisual é utilizada como estratégia de resistência e desenvolvimento da educação escolar indígena. Busca-se analisar como o audiovisual pode colaborar para o fortalecimento dos jovens indígenas estudantes do ensino médio, dos acadêmicos da educação superior, dos professores indígenas e das lideranças indígenas. A metodologia para a produção científica a respeito das atividades extensionistas define-se como participação observante, nos termos de Loïc Wacquant (2002), visto que a equipe participa da produção dos vídeos e é composta, em parte, por estudantes indígenas que viveram em algumas dessas comunidades e, em parte, por estudantes e pesquisadores não indígenas. Assim, os observadores que descrevem estão inseridos no contexto observado. O observador torna-se um experimentador e a experimentação uma forma de observação. As entrevistas e as questões formuladas nas oficinas, que foram realizadas durante o projeto de extensão, também serviram como ferramenta de apoio para compor a metodologia e, assim, compreender melhor a respeito das dinâmicas pedagógicas das escolas indígenas. Optamos por apresentar trechos de algumas falas que sintetizam algumas conclusões das 
comunidades participantes do projeto nos eixos bilinguismo, currículo, gestão e participação da comunidade e formação de lideranças.

A equipe é composta por dois professores, sendo um do serviço social e outra da comunicação, um graduado em serviço social, um mestrando em comunicação e quatro estudantes de graduação das áreas de jornalismo, letras e ciências sociais, sendo três destes indígenas, dois Kaingang e um Guarani. É importante mencionar que toda a produção seguiu as exigências do Comitê de Ética em Pesquisas, o que inclui elaborar os Termos de Consentimento e a solicitação da autorização de cada sujeito também nas gravações. ${ }^{2}$

\section{Conhecendo as comunidades e as escolas}

O projeto atendeu cinco terras indígenas da região Norte do Paraná, onde estão instaladas oito escolas estaduais. Entre os professores que trabalham nessas escolas, os indígenas já são maioria. ${ }^{3}$ No entanto, as funções de direção e de coordenação pedagógica ainda são ocupadas, em grande parte, por não indígenas:

Quadro 1 - Participação indígena nas escolas.

\begin{tabular}{|l|c|c|c|c|c|}
\hline \multicolumn{1}{|c|}{ Terra Indígena } & Direção & Pedadogo & $\begin{array}{c}\text { Professores não } \\
\text { indígenas }\end{array}$ & $\begin{array}{c}\text { Professores } \\
\text { indígenas }\end{array}$ & $\begin{array}{c}\text { Número de alunos } \\
\text { atendidos }\end{array}$ \\
\hline $\begin{array}{l}\text { Apucaraninha } \\
\text { Escola João Kavagtan } \\
\text { Vergilho }\end{array}$ & Indígena & 1 indígena & 2 & 16 & 236 \\
\hline $\begin{array}{l}\text { Apucaraninha } \\
\text { Colégio Benedito } \\
\text { Rokag }\end{array}$ & $\begin{array}{c}\text { Não } \\
\text { indígena }\end{array}$ & 1 indígena & 10 & 6 & 267 \\
\hline $\begin{array}{l}\text { Apucaraninha } \\
\text { Barreiro }\end{array}$ & $\begin{array}{c}\text { Não } \\
\text { indígena }\end{array}$ & $\begin{array}{c}1 \text { não } \\
\text { indígena }\end{array}$ & 2 & 3 & 40 \\
\hline $\begin{array}{l}1 \text { não } \\
\text { Onofo de Antonina }\end{array}$ & $\begin{array}{c}\text { Não } \\
\text { indígena }\end{array}$ & 10 & 12 & 97 \\
\hline $\begin{array}{l}\text { Barão de Antonina } \\
\text { Colégio Rael Vynhkag }\end{array}$ & $\begin{array}{c}\text { Não } \\
\text { Indígena }\end{array}$ & $\begin{array}{c}1 \text { não } \\
\text { indígena }\end{array}$ & 3 & 25 & 25 \\
\hline São Jerônimo da & Indígena & 1 indígena & 25 & 30 \\
\hline
\end{tabular}

2 CAAE 90751018.0.0000.5231.

${ }^{3}$ A comunidade de São Jerônimo da Serra, que também fica na região, preferiu não participar. 


\begin{tabular}{|c|c|c|c|c|c|}
\hline $\begin{array}{l}\text { Serra } \\
\text { Cacique kofej }\end{array}$ & & $\begin{array}{c}2 \text { não } \\
\text { indígenas }\end{array}$ & & & \\
\hline $\begin{array}{l}\text { Pinhalzinho } \\
\text { Escola Yvyporã }\end{array}$ & Indígena & $\begin{array}{c}1 \text { não } \\
\text { indígena }\end{array}$ & 8 & 4 & 37 \\
\hline $\begin{array}{l}\text { Laranjinha } \\
\text { Escola Tudja } \\
\text { Nhanderu }\end{array}$ & $\begin{array}{c}\text { Não } \\
\text { Indígena }\end{array}$ & 1 indígena & 2 & 7 & 31 \\
\hline $\begin{array}{l}\text { Posto Velho } \\
\text { Escola Nimboeaty M } \\
\text { Awa Tirope }\end{array}$ & $\begin{array}{c}\text { Não } \\
\text { Indígena }\end{array}$ & $\begin{array}{c}1 \text { não } \\
\text { indígena }\end{array}$ & 2 & 6 & 13 \\
\hline Total & $\begin{array}{c}9 \\
33 \% \\
\text { indígenas }\end{array}$ & $\begin{array}{c}11 \\
45 \% \\
\text { indígenas }\end{array}$ & $\begin{array}{l}44 \\
\text { Professores não } \\
\text { indígenas }\end{array}$ & $\begin{array}{c}3 \\
\text { Professores } \\
\text { indígenas }\end{array}$ & $\begin{array}{c}1.013 \\
\text { Estudantes } \\
\text { indígenas }\end{array}$ \\
\hline
\end{tabular}

Fonte: Levantamento do Projeto Nhanderekô Eg Kanhró junto às escolas (2019).

A Terra Indígena Apucaraninha está localizada a cerca de 90 quilômetros de Londrina, município ao qual faz parte. De acordo com o Censo de 2010, na comunidade vivem aproximadamente 1.420 pessoas, somando um total de 350 famílias (IBGE, 2010). Cercada pelos rios Apucarana, Apucaraninha e Tibagi, a paisagem delineada por morros, ainda abriga o salto do Apucaraninha, uma queda d'água de 126 metros. Alguns quilômetros antes da cachoeira, o rio foi represado em duas partes para a construção de uma usina hidrelétrica na década de 1940. O território, atualmente de 5.574 hectares, é dividido entre sede, Água Branca, Serrinha e Barreiro.

Na Terra Indígena do Apucaraninha existem três escolas. Na sede, há uma escola para o ensino fundamental e médio e outra para educação infantil. O Colégio Benedito Rokag, na sede, foi inaugurado em 2013 e atende aproximadamente 267 alunos do ensino fundamental e médio, entre os períodos matutino e vespertino. Nesta escola, as aulas são ministradas em Português na maioria dos casos. Já a escola João Kavagtan Vergilio, antes um colégio rural, foi inaugurada como escola indígena em 2009, e tem aproximadamente 236 alunos matriculados entre manhã e tarde nas séries iniciais, sendo que esta trabalha exclusivamente na Língua Kaingang. Da mesma forma ocorre no Barreiro, onde há outra escola para educação infantil onde a primeira língua ensinada é Kaingang.

Na Terra Indígena de São Jerônimo, a 110 quilômetros de Londrina, vivem aproximadamente 495 pessoas e três etnias: Kaingang, Guarani e Xeta. O território, atualmente de 1.339,34 hectares, fica a menos de dois quilômetros da cidade de São 
Jerônimo da Serra. Nessa comunidade, há um colégio que funciona em dois locais e que atende 262 alunos, entre crianças da educação infantil até os jovens do terceiro ano do ensino médio, atuando em três turnos. Nesta edição do projeto, a comunidade preferiu não participar.

Situada no topo da serra, a Terra Indígena Barão de Antonina, a 108 quilômetros de Londrina, abriga aproximadamente 498 pessoas e também faz parte do município de São Jerônimo da Serra. Assim como o Apucaraninha, parte do Barão fica às margens do Rio Tibagi, só que do outro lado, com a área de 3.751 hectares. No Barão são duas escolas: a Onofre Kanhgren, construída em 1984, que atende alunos do 40 ano da educação infantil até - 9o ano do ensino fundamental, com aproximadamente 97 alunos matriculados no matutino e no vespertino; e a Escola Estadual Rael Vynhkag, criada mais recentemente, que tem aproximadamente 30 alunos entre matutino e vespertino. Nessas escolas, o ensino da Língua Indígena se limita a disciplinas que envolvem aspectos culturais.

No município de Santa Amélia, a 132 quilômetros de Londrina, está a Terra Indígena Laranjinha. Seu território tem mais de mil hectares onde vivem aproximadamente 184 pessoas da etnia Guarani Nhandewa. A escola se chama Tudja Nhanderu, teve início em 1939, mas foi municipalizada em 1999 e depois estadualizada em 2008. Atualmente tem 31 alunos matriculados. Com dois turnos, sendo eles matutino e vespertino, o colégio atende apenas até o 5 o ano do ensino fundamental.

A Terra Indígena Posto Velho está em processo de retomada há mais de 10 anos. Sabe-se que no início eram 23 famílias, mas atualmente há cerca de 100 pessoas lutando pela demarcação do território próximo à cidade de Santa Amélia, e quase às margens do Rio Laranjinha, a 140 quilometros de Londrina aproximadamente. Mesmo estando em processo de demarcação, a Terra Indígena Posto Velho conta com uma escola. Inaugurada em 2003 ainda em um galpão e com o nome de Nimboeaty $M$ Awa Tirope, o colégio da comunidade tem 13 alunos matriculados; atende apenas até o 4으 ano do ensino fundamental, nos períodos matutino e vespertino. Em 2017, foi inaugurada sua sede atual.

A Terra Indígena Pinhalzinho, tem aproximadamente 129 pessoas vivendo em seu território com área total de 593 hectares, situada no município de Tomazina, a 171 quilômetros de Londrina. A Escola Yvyporã, que começou a funcionar em 1982, atende até o 9o ano do ensino fundamental e tem aproximadamente 37 alunos matriculados; estes divididos entre os dois turnos em que o colégio funciona: matutino e vespertino. 
Algumas iniciativas chamam a atenção no que se refere ao desenvolvimento da educação escolar indígena nessas escolas. A escola Ywy Porã do Pinhalzinho, liderada por um diretor Guarani, visa atender as especificidades da comunidade, com atividades educacionais voltadas para a cultura Guarani Nhandewa e fazendo correlações do conhecimento científico dos não indígenas aos saberes tradicionais da comunidade. Já na Terra Indígena Apucaraninha, a escola João Kavagtan Vergilho trabalha os conteúdos apenas na língua materna da comunidade, o Kaingang, além de ensinar a estrutura linguística da língua. E no Colégio Benedito Rokag, além de ter aulas de Kaingang (estrutura linguística), os alunos reuniram jovens da comunidade para formar um grupo de danças e cantigas tradicionais. Para além da dança e da cantiga, o grupo preserva ainda as marcas étnicas Kaingang e algumas vestimentas tradicionais que são usadas durante as apresentações culturais. No calendário das duas escolas consta a Festa do Pari, comemoração que busca reviver o ritual de pesca com armadilhas, tradicional da cultura Kaingang, aliado a danças, cantingas e comidas tradicionais. A festividade dura cerca de cinco dias. As demais escolas indígenas possuem disciplinas específicas da língua materna de sua comunidade e, no caso da escola Cacique Kofej, da Terra Indígena de São Jerônimo, onde vivem indígenas Kaingang, Guarani e Xetá, cada etnia tem aula da sua respectiva lingua materna.

\section{Formatando as Oficinas de Vídeo}

Durante cinco meses, a equipe, composta inicialmente por sete pessoas, estudou temas como: a presença indígena na formação do Brasil, educação escolar indígena, características das etnias Kaingang e Guarani, representação midiática dos povos indígenas, experiências de produção audiovisual - como o projeto Vídeo nas Aldeias. Numa segunda etapa, houve a primeira visita de apresentação da equipe às Terras Indígenas. Entre os estudantes indígenas que compõem o grupo há uma Guarani da Terra Indígena de Barão de Antonina, um Guarani da Terra Indígena de Pinhalzinho e um Funiô/Kaingang da Terra Indígena de Apucaraninha, que auxiliaram nos contatos com as lideranças e professores das comunidades. Para a formatação das oficinas de vídeo, a equipe baseou-se nas ideias de Paulo Freire sobre a educação emancipadora, considerando que:

[...] conhecer não é o ato através do qual um sujeito transformado em objeto, recebe dócil e passivamente os conteúdos que outro the dá ou Ihe impõe. 0 conhecimento pelo contrário, exige uma presença curiosa do sujeito em face do mundo. Requer sua ação transformadora sôbre a realidade. Demanda uma busca 
constante. Implica invenção e reinvenção [...] no processo de aprendizagem, só aprende verdadeiramente aquêle que se apropria do aprendido, transformando-o em apreendido, com o que pode, por isso mesmo, reinventá-lo; aquêle que é capaz de aplicar o aprendido-apreendido a situações existenciais concretas. Pelo contrário, aquêle que é "enchido" por outros de conteúdos cuja inteligência não percebe, de conteúdos que contradizem a própria forma de estar em seu mundo, sem que seja desafiado, não aprende (FREIRE, 1985, p. 16).

Por outro lado, a inspiração de como problematizar as questões importantes para a educação escolar indígena veio dos modos de vida dos próprios indígenas, que, em geral, costumam trocar experiências e refletir juntos sobre o passado, o presente e as aspirações para o futuro. Para Tassinari (2001), a escola indígena está frequentemente envolvida em um movimento de articulação entre os conhecimentos científicos e os indígenas, um espaço onde transitam conhecimentos e tradições que são usadas e compreendidas de diferentes maneiras. Essas trocas de conhecimentos redefinem as identidades dos grupos envolvidos no processo, indígenas e não indígenas.

Impactos econômicos, políticos e culturais ocorrem das terras indígenas a partir da criação de uma escola. E esse desdobramento de como se dão os processos de conhecimento estará intimamente ligado ao próprio processo constitutivo da comunidade. Há sempre o perigo da homogeneização da cultura, dos conhecimentos indígenas e dos próprios indígenas. Nesse sentido, Cohn afirma que para entender as demandas da escolarização, suas possibilidades e seu impacto na vida das comunidades, é necessário um olhar para o que é particular, um olhar cuidadoso e local (COHN, 2016).

As trocas e transmissões do saber tradicional geralmente se dão pela oralidade. Nesse sentido, surgiu a ideia de começarmos as atividades com uma roda de apresentações e de conversa. Após as apresentações individuais, era apresentado o projeto, mencionando aspectos legais da educação indígena e falando sobre os objetivos do vídeo a ser produzido, sendo o principal deles o de refletir sobre a escola indígena que se tem e a que se deseja ter.

Em seguida, iniciava-se a roda de conversa com os roteiros de questões problematizadoras propostas pela equipe, seguindo eixos de reflexão para os quais eram escolhidos relatores. Esses eixos foram os seguintes: bilinguismo, currículo, gestão e participação da comunidade, e formação de lideranças. Após selecionados os relatores, o grupo composto por professores, diretores, caciques e lideranças passava a conversar sobre as seguintes questões, previamente propostas, e outras que pudessem surgir no momento. As conversas balizaram como era a escola para os indígenas no passado e como é na atualidade. Também buscou-se apreender as especificidades da escola de cada comunidade, 
a organização do currículo, como é o ensino da língua Guarani/Kaingang e ainda as aspirações da escola desejada para o futuro, seu papel na formação de lideranças. A questão do profissional da educação atuando como professores e gestores dessas diferentes escolas também foi abordada.

Ao longo dessa roda de conversa, os relatores dos eixos propostos sintetizavam os principais pontos de convergência nas ideias do grupo. Após debates entre os grupos, os relatores contavam as conclusões e esta fala era gravada em vídeo.

Paralelamente, outra oficina era realizada com os estudantes, seguindo uma dinâmica parecida. Na roda de conversa, foram apresentadas as perguntas guias sobre as dificuldades encontradas pelos jovens na escola, a importância em estudar numa escola indígena e quais as diferenças de abordagem com as escolas não indígenas. Também falouse sobre os planos após a conclusão do ensino médio e as expectativas ou ausências de expectativas em relação à universidade.

Ao final, os relatores contavam o que concluíram, sintetizando cada ponto. As respostas foram gravadas com celulares. Os vídeos foram copiados pela equipe para compor o documentário. Para concluir o processo, também foram gravadas imagens externas de cada Terra Indígena participante, com tomadas gerais da comunidade, a fachada e as instalações da escola, assim como tomadas das oficinas, das salas de aula durante as atividades letivas.

Após essa primeira etapa, o trabalho de edição foi feito na universidade, com a participação dos estudantes indígenas que integram a equipe, seguindo as sugestões da comunidade escolar. Com a conclusão de uma primeira versão do vídeo, esperamos ter a oportunidade de discutir a edição com representantes das escolas participantes, para então concluirmos a edição final do material.

\section{A apropriação da comunicação}

Um trabalho de referência no Brasil quanto à produção audiovisual em comunidades indígenas é o projeto Vídeo nas Aldeias (VNA), do indigenista Vincent Carelli. Desde 1997, o projeto passou a oferecer oficinas de produção audiovisual aos indígenas para que eles mesmos retratassem a realidade em suas comunidades. Em favor da identidade indígena, reconhecimento e manutenção dos costumes tradicionais e luta pelos territórios, o projeto foi pioneiro em trazer à tona a discussão no âmbito da comunicação, colocando em 
pauta a discussão sobre as realidades e as especificidades das mais diversas etnias existentes no país. Ainda que Vicent, idealizador do projeto, não fosse indígena - o que denota um movimento externo à realidade dos povos originários -, a dinâmica do processo de produção audiovisual se deu de forma endógena, com os próprios indígenas atuando na produção de suas narrativas (ARAÚJO, 2015).

Em uma das edições do Vídeo nas Aldeias, o professor indígena e realizador formado pelo projeto, Isaac Pinhanta, da etnia Ashaninka, comenta sobre esse processo:

\begin{abstract}
Se o vídeo vem ajudar a gente a se organizar, se ele traz alguma mudança, somos nós que estamos mudando, não é ninguém que vem de lá de fora. Alguém pode vir só nos orientar como usar, mas quem vai usar esses instrumentos somos nós. E se houver alguma mudança, somos nós mesmos que estamos fazendo ela acontecer. Então a gente quer entender tudo isso, a gente quer entender esse processo, porque a gente só vai se defender quando entender esse processo e esses instrumentos. $O$ computador, a escrita, a tv e o vídeo são instrumentos ideais para aprofundar o nosso conhecimento (PINHANTA, 2004).
\end{abstract}

A forte ligação com a oralidade e corporalidade permite ao audiovisual uma afinidade com as culturas indígenas.

\footnotetext{
Sem a intermediação da escrita, com a produção audiovisual esses povos passam da linguagem oral diretamente para a audiovisual, incitando mudanças na posição (de receptores a produtores), na forma (de documentários etnográficos a estilos variados de produção audiovisual) e no conteúdo (de 'índios puros' projetados pela sociedade nacional a 'sujeitos reais', os quais narram suas culturas) (PEREIRA, 2010).
}

A autorrepresentação é importante para que os indígenas se apropriem e interajam com as tecnologias cognitivas, transformando o modo como eles se veem e são vistos. Esse método desenvolve ainda a autoconsciência de como se constroem o imaginário e a memória do que é ser indígena.

Outro exemplo, mais recente, mas que é muito análogo à proposta do VNA, é a experiência da Rádio Yandê, a primeiro rádio online indígena do Brasil, a partir de 2013, atuando não apenas como uma canal de informação sobre as pautas indígenas atuais, mas também no sentido de comunicar (admitindo o significado de partilhar o conhecimento) as comunidades indígenas. A Yandê compartilha produções, inclusive audiovisuais, de diversas etnias do Brasil que se apropriam da comunicação para compartilhar seus conhecimentos tradicionais e resistir como indígenas dentro de uma sociedade repleta de preconceitos e ideias colonizadas a respeito do que é ser indígena (RIBEIRO, 2017, 2018). A webradio tem o intuito de partilhar seus conteúdos entre as comunidades, criando assim uma rede de 
conhecimentos entre as etnias, mas, sobretudo, de descolonizar a imagem estereotipada dos povos indígenas.

A partir desses exemplos, que se somam a vários outros que estão atuantes nos mais diversos canais de comunicação (especialmente canais online), as comunidades indígenas têm compreendido a importância de se apropriarem de aparatos tecnológicos e criarem suas próprias narrativas, em um movimento endógeno, a partir de um olhar étnicocomunitário. Dessa forma, as narrativas produzidas pelos próprios indígenas admitem um caráter diferenciado do que é proposto e noticiado pela mídia hegemônica, uma vez que contam a partir de si mesmos e de seus territórios.

A apropriação da comunicação audiovisual por parte das comunidades indígenas no projeto Nhanderekô Eg Kanhró necessita, antes de tudo, englobar a compreensão das relações sociais produzidas dentro dos territórios indígenas através da educação escolar indígena. Uma escola em território indígena tem o dever de atender as demandas não apenas da educação básica, mas também para a manutenção da cultura indígena, ligando os conhecimentos da educação básica com os conhecimentos tradicionais.

Desta forma, a presença de professores e pedagogos indígenas à frente da educação escolar indígena é imprescindível para a autonomia pedagógica junto às especificidades da cultura e dos costumes tradicionais, além da afirmação da identidade indígena na atualidade. De acordo com a Constituição Federal de 1988, a educação escolar indígena tem o intuito de manter uma escola específica, bilingue, intercultural, diferenciada e comunitária, porém a realidade é diferente. Segundo dados coletados pelos integrantes do projeto Entre os saberes da escola indígena e da universidade: a comunicação audiovisual como elemento de expressão, articulação e fortalecimento da organização dos professores indígenas - Nhanderekô Eg Kanhró, 35\% ${ }^{4}$ dos professores das nove escolas da região norte do Estado do Paraná não são indígenas. Esses números levam à reflexão de que a educação escolar indígena enfrenta alguns problemas no que diz respeito ao cumprimento da Lei de Diretrizes e Bases da Educação Nacional (LBD) 5 .

Para isso, a qualificação específica de professores indígenas nas mais variadas áreas do conhecimento científico, a fim de, principalmente, aplicá-los na educação escolar básica

\footnotetext{
${ }^{4}$ As nove escolas do Norte do Paraná concentram, no total, 127 professores, dos quais 44 não indígenas e 83 professores indígenas.

${ }^{5}$ A Lei № 9.394 garante o direito à educação intercultural, comunitária, específica e diferenciada, preservando os direitos conquistados na Constituição Federal de 1988 (CONFERÊNCIA NACIONAL DE EDUCAÇÃO ESCOLAR INDÍGENA, 2016).
} 
indígena é imprescindível, uma vez que os limites da escola indígena não se dão pelos seus muros, mas se compreende em toda a extensão da aldeia indígena, denotando uma vivência em comunidade para o compartilhamento do saber. Ainda, a aplicabilidade de uma escola indígena intercultural requer que os conhecimentos científicos, tidos como universais, dialoguem com os conhecimentos e saberes tradicionais (BRAND; CALDERONI, 2012).

Mas também, algumas experiências na área da comunicação por parte das comunidades indígenas mostram que o compartilhamento do saber tem tomado outras dimensões, e que as comunidades indígenas buscam atualizar sua educação por meio da comunicação. Com a utilização de aparatos tecnológicos, organização em redes sociais, apropriação dos meios e canais de comunicação, as comunidades indígenas têm a oportunidade de expandir seus conhecimentos e seus territórios a outras etnias, garantindo mobilização e apoio, além de alcançar a comunidade não indígena.

Outro ponto a se considerar no que diz respeito à apropriação da comunicação pelas comunidades indígenas, levando em conta a experiência do projeto Nhanderekô Eg Kanhró, da Universidade Estadual de Londrina, é a contribuição que a comunicação agrega à educação. A partir da utilização do audiovisual, as etnias Kaingang, Guarani e Xetá, que participaram do projeto, ttiveram a oportunidade de elaborar narrativas sobre a escola indígena que desejam. As rodas de conversa tiveram como proposta organizar o pensamento comunitário dos educadores das diversas escolas e, ao gravá-las em um vídeo que possa ser apresentado aos novos integrantes da escola, servindo de guia para alinhar essa construção coletiva. Ainda, o audiovisual "dá a possibilidade da história e da língua de seu povo ficarem guardadas para sempre." (DI FELICE; PEREIRA, 2017, p. 52), uma vez que a "capacidade expressiva das imagens engloba alguns dos componentes fundamentais da comunicação indígena: a oralidade e o corporalidade." (DI FELICE; PEREIRA, 2017, p. 53).

As imagens tomadas pelos indígenas em suas narrativas admitem uma dimensão não apenas de demarcação do local que está sendo descrito nos vídeos, mas também assume o papel de contextualizar a identidade étnica e a relação da comunidade com o espaço geográfico, dando margem a um novo tipo de educação aos povos indígenas, uma educação pautada no poder da comunicação para sua presença de resistência de afirmação identitária nas redes digitais, permitindo maior diálogo com as demais esferas da sociedade em um movimento intercultural.

Essas relações das comunidades indígenas, a partir da comunicação audiovisual e de outros meios de comunicação, que constituem uma rede intercultural de saberes, dá a 
dimensão de um novo habitar 6 que "não se restringe ao residir ou apenas ao estar" (FRANCO, 2017, p. 93), mas também pode ser entendido como o ato de construir relações/conexões.

Assim, tanto a educação indígena quanto a apropriação da comunicação como instrumento de fortalecimento, manutenção e resistência da cultura e da identidade indígena se interligam e se fazem de extrema importância para a educação escolar indígena, uma vez que proporciona expandir as especificidades e as realidades das etnias em questão.

\title{
A escola Indígena que Queremos
}

As oficinas do projeto serviram para refletir, organizar coletivamente as ideias e amadurecer os sonhos, que ao final eram registrados pela câmera e pelo microfone. Como é característico dos povos indígenas, o conhecimento e a sabedoria costumam se basear nas experiências de vida.

Para falar do bilinguismo, destacamos o depoimento do professor bilingue, Manoel Felisbino ${ }^{7}$, do Apucaraninha, onde a língua materna é o Kaingang e o ensino fundamental de séries iniciais é somente na língua indígena. Muito antes disso no entanto, Felisbino, falante do Kaingang desde pequeno, aos 15 anos foi morar no Rio Grande do Sul, onde aprendeu a ler e a escrever o português. Em 1982, voltou para sua comunidade de origem para ensinar os demais. Não só a falar, mas também a ler e escrever em Português e Kaingang. Ele deixa um recado aos professores indígenas:

\begin{abstract}
Então, eu digo para vocês professores: trabalhar unidos para que a gente consiga o que a gente quer. E que os pais das crianças também ensinem seus seus filhos junto com a gente a falar e ler. E não vamos deixar de ser indígenas, não vamos deixar nunca [...] eu fico feliz, quando eu sei que vocês tão tentando ajudar, então a nossa obrigação é aprender as duas línguas: Português e Kaingang. E também a Secretaria da Educação e o Núcleo Regional tem que nos respeitar quando a gente tenta fortalecer a nossa cultura. Às vezes eles não gostam, mas aqui a nossa língua é a nossa cultura e nós nunca vamos desanimar.
\end{abstract}

Na Terra Indígena do Pinhalzinho, a escola tem uma experiência inovadora de adaptar o dia a dia da escola aos ciclos do calendário Guarani. Isso é possível porque além do diretor da escola ser Guarani, o cacique e a comunidade discutem e acompanham o

\footnotetext{
6 Este conceito é abordado em toda a obra de Di Felice e Pereira (2017) a partir do entendimento heideggeriano do termo.

7 Depoimento concedido à equipe do Projeto Nhanderekô Eg Kanhró de Londrina pelo professor bilingue, Manoel Felisbino, do Apucaraninha
} 
desenvolvimento das atividades da escola. Como diz o cacique, sr. Sebastião Mário Alves ${ }^{8}$, a escola Guarani abrange todo o território e não está limitada por cercas:

[...] a floresta pra nós é uma escola... escola não é só lá, a escola do branco... nessa escola aprendemos até com os passarinhos, com as formigas, com o vento, e a nossa cultura é desse jeito e essa é a diferença que nós queria que tivesse [...] no tempo dos meus pais, a nossa saúde pra nós era a educação, quando ia pra minha escola no mato, aprender alguma coisa, quando meu pai ia me ensinar que fruta podia comer, qual era remédio [...] eu não tive faculdade, minha faculdade foi na floresta, meu pai que foi meu professor, minha mãe que foi minha professora e me ensinaram tudo que eu sei hoje [...] os jovens vai estudar lá fora e vem com outro jeito de viver.

Uma das questões que surgiram foi exatamente o fato que a maioria das comunidades oferecem somente as séries iniciais nas escolas situadas em Terras Indígenas. Isso obriga os jovens a se deslocarem muito cedo para a cidade, iniciando uma convivência imersiva em outra cultura e outro modo de educar, o que acaba, de certa forma, enfraquecendo os laços de sua formação com os costumes tradicionais. Essa convivência muito próxima, aumenta a complexidade no processo educativo. Até porque as próprias comunidades entendem que é preciso "falar a língua dos brancos" para se defender, ter acesso à tecnologia e ir para a universidade, protagonizar sua própria educação escolar e atendimento à saúde. Nas oficinas, também surgiu a discussão sobre novas formas de liderança, como os influenciadores digitais, por exemplo. Ao assistirem aos vídeos do youtuber Xavante e Guarani W'ariu e conhecerem iniciativas como a Webradio Yandê e a página Mídia Índia, os grupos abordavam a necessidade de estar presentes na internet. Como diz Reginaldo Alves ${ }^{9}$, da Terra Indígena do Pinhalzinho:

\footnotetext{
Bom, eu vejo que é fundamental nisso, ainda mais no contexto político da atualidade, o aluno tem que sair formador de opinião, formação de lideranças, formação de pensadores [...] a concorrência é muito forte, a tecnologia, hoje, compete demais com a oralidade do mais velho. O mais velho hoje não consegue mais sentar com uma criança, contar as histórias e os processos de luta.
}

\footnotetext{
${ }^{8}$ Entrevista concedida à equipe do Projeto Nhanderekô Eg Kanhró de Londrina, pelo professor bilingue Manoel Felisbino, 2019.

${ }^{9}$ Entrevista concedida à equipe do Projeto Nhanderekô Eg Kanhró de Londrina, por Reginaldo Alves da Terra Indígena do Pinhalzinho, em maio de 2019.
} 
A escola indígena vive, então, um paradoxo de ser um lugar de proteção à cultura indígena, mas, também, de acesso a novos dispositivos e formas de promover os conhecimentos tradicionais. O professor Claudinei Lourenço ${ }^{10}$, do Posto Velho, define:

Nimboeaty um lugar de aprender coisas. Então a gente nomeia como escola, mas, na verdade mesmo, a escola é a casa de reza, é onde o Txamõi oralmente transmite a sabedoria, tudo assim na língua, né? [...] A escola de hoje não pode ser um campo de concentração pra matar a cultura, ela tem que ser um campo especifico para fortalecer a cultura.

Para que essa escola indígena se fortaleça e articule tradição e inovação, as comunidades têm uma expectativa em relação ao retorno dos jovens que estão ingressando na universidade, especialmente como professores e médicos, para atuar nas comunidades promovendo as transformações necessárias e trabalhando a interculturalidade dos conhecimentos científicos e tradicionais.

No caso das oficinas com os estudantes do ensino médio, a participação foi bem abaixo da esperada, justamente pelo fato da maioria se deslocar diariamente para a escola na cidade, o que dificultou a compatibilidade de horários com a aplicação das oficinas. Entre os depoimentos dos jovens, destaca-se a presença constante de histórias de preconceito nas escolas urbanas, tanto por parte de colegas quanto de professores.

\section{Considerações Finais}

Neste artigo, buscamos refletir sobre o uso da comunicação audiovisual como estratégia de resistência e desenvolvimento da educação escolar indígena e analisar como o audiovisual pode colaborar para o fortalecimento dos jovens indígenas estudantes do ensino médio, dos acadêmicos da educação superior, dos professores indígenas e das lideranças indígenas. Como ainda nao foi possível a avaliação dos resultados junto das comunidades, podemos relatar o que vimos acontecer, ou seja, o processo de produção dos vídeos desencadeou discussões, promoveu o diálogo e amadureceu formulações sobre os temas propostos.

Para os estudantes indígenas participantes da equipe de produção, foram vários depoimentos que denotaram o fortalecimento identitário, assim como de seus vínculos e responsabilidades enquanto integrantes de um movimento de resistência, representantes

\footnotetext{
${ }^{10}$ Entrevista cedida à equipe do Projeto Nhanderekô Eg Kanhró de Londrina, em junho de 2019, pelo professor Claudinei Lourenço.
} 
de um novo momento protagonizado pelos indígenas na construção de discursos e de conhecimento sobre suas comunidades.

Atualmente as escolas indígenas atuam de forma desarticulada entre si. Entre as nove escolas, a do Pinhalzinho tem um Projeto Político Pedagógico (PPP) e currículo diferenciados, uma vez que os conteúdos aplicados em aula são voltados para os saberes tradicionais, mesmo quando se trata do conhecimento do não indígena. Já as demais escolas apenas possuem um PPP diferenciado, focando no ensinamento da língua materna; como é o caso da escola de São Jerônimo que oferece três línguas distintas para atender as três etnias presentes naquela Terra Indígena. No Apucaraninha, o grupo de dança Nen Gã e a Festa do Pari são elementos fundamentais para cultivar e fortalecer os conhecimentos tradicionais, e ressaltam ainda mais a importância de se atender as especificidades de cada povo na educação escolar indígena. No entanto, há escolas que desconhecem essas iniciativas e acabam se atendo ao modelo de educação escolar do não indígena.

Acredita-se que a realização das oficinas de audiovisual e a produção de vídeos sobre as escolas e sobre as características da educação indígena que as comunidades aspiram implantar possam colaborar para essa integração, no sentido de sintetizar as especificidades e demandas da educação escolar indígena dessas escolas.

Percebeu-se no decorrer das oficinas que os profissionais indígenas da educação, assim como as lideranças, puderam estabelecer uma interlocução que no cotidiano da escola acaba não acontecendo. Com as rodas de conversa, foi possível colocar o funcionamento de suas escolas em perspectiva e pensar uma nova realidade. Nesse sentido, a equipe acredita que houve um estímulo, uma tomada de fôlego das pessoas envolvidas nas oficinas. Mais do que o vídeo como um resultado final, esse processo foi certamente muito rico, no sentido de "sonhar a escola indígena que queremos".

Por outro lado, espera-se que o vídeo finalizado colabore para a conscientização das próprias comunidades indígenas beneficiadas pelo projeto Nhanderekô Eg Kanhró no que diz respeito à reinvindicação dos direitos constitucionais para uma educação específica, diferenciada, bilingue e intercultural, uma vez as escolas indígenas se apresentam como "espaços estratégicos [para] melhorar suas condições de inserção, diálogo e de enfrentamento [...] sem abrir mão da afirmação de suas múltiplas indentidades e projetos de autonomia." (BRAND; CALDERONI, 2012).

A proposta é que o vídeo possa ser mostrado para novos profissionais, indígenas e não indígenas, que chegam para atuar nas escolas a cada ano, e aos próprios estudantes no 
ambiente escolar e em outros espaços da comunidade. No entanto, estando disponível na internet, poderá ser divulgado nas redes sociais por professores indígenas e não indígenas, projetando essa discussão para outros foruns.

Ainda, é possível que as narrativas audiovisuais contribuam na maior visibilidade à problemática educacional indígena e na sensibilização social sobre essa temática, assim como, nas palavras de Di Felice (2017), amplie os territórios indígenas nas redes digitais.

\section{Referências}

AMARAL, Wagner Roberto do. Indígenas nas universidades estaduais do Paraná: sujeitos, trajetórias e pertencimentos. In: AMARAL, W. R.; FRAGA, L.; RODRIGUES, I. C.; (org). Universidade para indígenas: a experiência do Paraná. Rio de Janeiro: FLACSO, 2016.

ARAÚJO, José. Cineastas indígenas, documentário e autoetnografia: um estudo do projeto vídeo nas aldeias. 2015. $270 \mathrm{f}$. Tese (Doutorado em Multimeios) - Instituto de Artes da UNICAMP, Universidade Estadual de Campinas, Campinas, 2015.

BRAND Antonio Jacó; CALDERONI, Valéria Aparecida Mendonça de Oliveira. Povos indígenas e formação acadêmica: ambivalências e desafios. Currículo sem Fronteiras, [S. I.], v. 12, n. 1, p. 85-97, jan./abr. 2012. Disponível em:

https://www.curriculosemfronteiras.org/vol12iss1articles/brand-calderoni.pdf. Acesso em: 11 nov. 2019.

COHN, Clarice. A cultura nas escolas indígenas. In: CUNHA, Manuela Carneiro da; CESARINO, Pedro de N. (org.). Políticas culturais e povos indígenas. São Paulo: Editora Unesp, 2016. p. 313-318.

CONFERÊNCIA NACIONAL DE EDUCAÇÃO ESCOLAR INDÍGENA, 2., 2018, Brasília. Anais [...]. Brasília: Ministério da Educação, Secretaria de Educação Continuada, Alfabetização, Diversidade e Inclusão (Secadi), 2016.

DI FELICE, Massimo. Atopia, redes digitais e a crise das formas do habitar do Ocidente. In: DI FELICE, M.; PEREIRA, E. S. (org.). Redes e ecologias comunicativas indígenas: as contribuições dos povos originários à teoria da comunicação. São Paulo: Paulus, 2017.

DI FELICE, Massimo; PEREIRA, Eliete S. Formas comunicativas do habitar indígena: a digitalização da floresta e o net-ativismo nativo no Brasil. In: DI FELICE, M.; PEREIRA, E. S. (org.). Redes e ecologias comunicativas indígenas: as contribuições dos povos originários à teoria da comunicação. São Paulo: Paulus, 2017.

FRANCO, Thiago C. Redes de redes e a forma comunicativa do habitar Krahô. In: DI FELICE, M.; PEREIRA, E. S. (org.). Redes e ecologias comunicativas inddígenas: as contribuições dos povos originários à teoria da comunicação. São Paulo: Paulus, 2017.

FREIRE, Paulo. Extensão ou comunicação? São Paulo: Paz e Terra, 1985. 
IBGE. Censo demográfico populacional, 2010. Rio de janeiro: IBGE, 2010. Disponível em: https://censo2010.ibge.gov.br/. Acesso em: 16 mar. 2019.

PEREIRA, Eliete S. Mídias nativas: a comunicação audiovisual indígena: o caso do projeto Vídeo nas Aldeias. C-legenda, Niterói, n. 23, p. 61-72, nov. 2010. Disponível em: http://www.ciberlegenda.uff.br/index.php/revista/article/view/133/49. Acesso em: 16 mar. 2019.

PINHANTA, Isaac. Você vê o mundo do outro e olha para o seu. Rio de Janeiro: Petrobras, abr. 2004. Disponível em: http://www.videonasaldeias.org.br/2009/ biblioteca.php?c=23. Acesso em: 16 mar. 2019.

RIBEIRO, Lucas Fernando; KASEKER, Monica Panis. Webradio Yandê e a descolonização da mídia. In: CONGRESSO BRASILEIRO DE CIÊNCIAS DA COMUNICAÇÃO - INTERCOM 2017, 40., 2017, Curitiba. Anais [...]. São Paulo: Intercom, 2017. Disponível em: http://portalintercom.org.br/anais/nacional2017/resumos/R12-1867-1.pdf. Acesso em: 16 mar. 2019.

RIBEIRO, Lucas Fernando. A experiência da Webradio Yandê como etnomídia em um contexto de convergência midiática. In: CONGRESSO BRASILEIRO DE CIÊNCIAS DA COMUNICAÇÃO - INTERCOM 2018, 41, Joinville. Anais [...]. São Paulo: Intercom, 2018. Disponível em: http://portalintercom.org.br/anais/nacional2018/resumos/R13-1554-1.pdf. Acesso em: 16 mar. 2019.

TASSINARI, Antonella Maria Imperatriz. Escola indígena: novos horizontes teóricos, novas fronteiras de educação. In: SILVA, Aracy L. da; FERREIRA, Mariana K. L. (comp.). Antropologia, história e educação: a questão indígena e a escola. São Paulo: Global, 2001. p. 45-70.

WACQUANT, Loïc. Corpo e alma: notas etnográficas de um aprendiz de boxe. Rio de Janeiro: Relume Dumará, 2002. 